\title{
Vibration Testing of a Carbon Composite Fuselage
}

\author{
J. Simsiriwong and R. W. Sullivan \\ Department of Aerospace Engineering \\ Mississippi State University, Mississippi State, MS 39762
}

\section{American Society for Composites \\ $\mathbf{2 3}^{\text {rd }}$ Technical Conference \\ Memphis, TN}

9-11 September, 2008

\begin{abstract}
This paper describes the details of an experimental investigation focusing on the vibration characteristics of a composite fuselage structure of an ultralight unmanned aerial vehicle (UAV). The UAV has a total empty weight of $155-\mathrm{lb}$ and an overall length of approximately $20.6-\mathrm{ft}$. The fuselage structure consists of the fuselage body with an integrated vertical stabilizer. All structural components are fabricated from oven-cured laminated carbon composite materials using uniaxial and biaxial prepreg fabric. In the current effort, the modal characteristics of the fuselage structure are determined for a free-free configuration which is simulated by suspending the test structure from its wing attachment points through the use of springs. A centrally located shaker system is used to induce vertical oscillations in the structure, which is instrumented with nineteen dual axis accelerometers. Dynamic properties such as the frequency, damping and associated mode shapes are obtained for aeroelastic analysis. The design and implementation of the vibration tests along with the experimental results are presented.
\end{abstract}

\section{INTRODUCTION}

In recent years, unmanned aerial vehicles (UAVs) have gained much interest as an alternative instrument in both military and civil aviation as well as scientific research particularly for intelligence, surveillance, and reconnaissance missions that are impractical for manned aircrafts. The aircraft of interest in this study is based on the design of an unmanned ultra-light sensor platform which is an integrated carbon-composite sailplane and the unmanned systems technology.

Jutima Simsiriwong, Department of Aerospace Engineering, Mississippi State University, Mississippi State, MS 39762, USA.

Rani W. Sullivan, Department of Aerospace Engineering, Mississippi State University, Mississippi State, MS 39762, USA. 
The aircraft consists of four primary components: the fuselage body with an integrated vertical stabilizer, a horizontal stabilizer, and the right and left wings. All aircraft structural components are made of laminated carbon composite materials with both uniaxial and biaxial prepreg fabrics. The parts are individually fabricated using precision molds and oven cured.

Although the UAV for this activity is considered an ultralight, its structural components were designed based on FAR Part 23 airworthiness standards for a normal category airplane. In order to measure the static and dynamic response of the vehicle, a series of structural tests are performed [1]. This paper describes the details of an experimental investigation focusing on ground vibration testing of the fuselage structure to obtain its vibration characteristics which includes natural frequencies, mode shapes, and damping coefficients. Description of the fuselage structure, material system and experimental method are described in the following sections. Additionally, a brief overview of the analytical methodology is given and results from the vibration tests are presented.

\section{DESCRIPTION OF FUSELAGE STRUCTURE}

Figure 1 shows the CAD model of the UAV. Inspired by the design of a powered sailplane, the UAV is equipped with a reciprocating engine, which is mounted on a pylon behind the cockpit (sensor bay) and can be retracted inside the fuselage when the UAV operates in glider mode. The fuel supply to the engine comes from sealed tanks inside the wings.

The fuselage body is comprised of left and right shells plus two frames, FF1 and FF2, which are located behind the sensor bay that encloses the propulsion system. The vertical stabilizer is an integral part of the fuselage whereas the horizontal stabilizer is mounted over a circular tube and two short rods protruding through the vertical stabilizer. The fuselage/tail body measures 247 -in. from the fuselage nose to the trailing edge of the vertical stabilizer. From its root to its tip, the vertical stabilizer measures 50.2-in. with a root chord dimension of 12.9-in. and maximum airfoil thickness of 4.4-in. at the root chord.
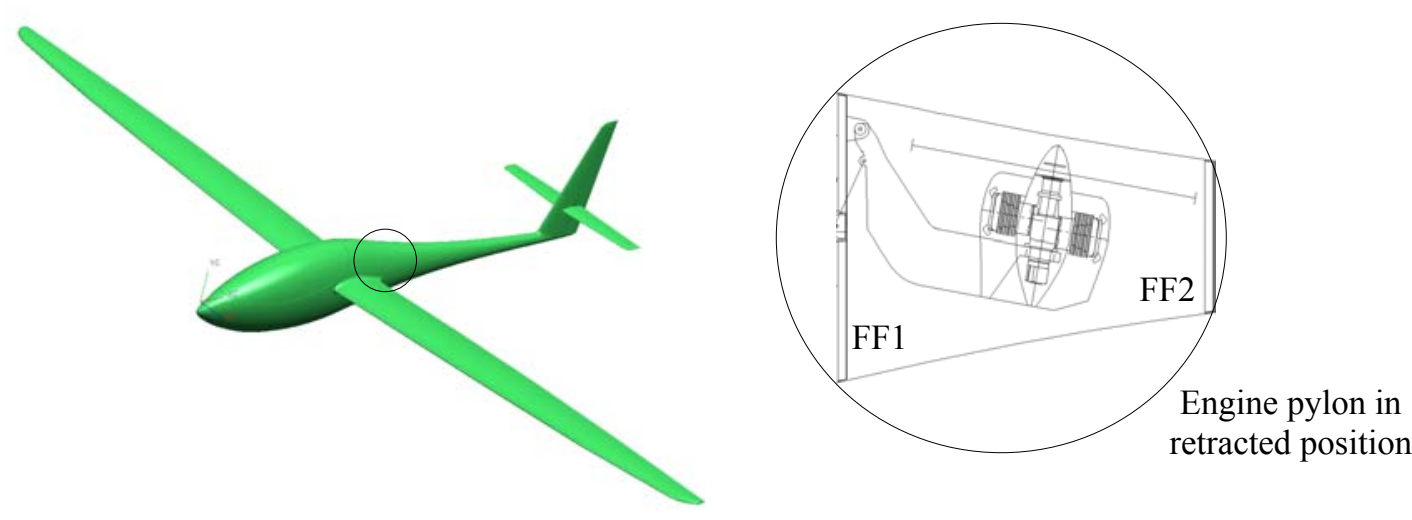
The fuselage/ tail structure is made from prepreg materials utilizing both unidirectional and woven carbon-fiber reinforced polymer composite fabrics. The semimonocoque fuselage structure is of multi-ply laminate construction except in the area around the sensor bay (denoted as region 10 in Figure 2), which is of sandwich construction using a 0.25 -in. thick honeycomb core. The skins of the vertical stabilizer are also of sandwich construction using 0.125 -in thick, low density Dyvinicel foam core. Material properties of the CFRP fabric are given in Table I and the laminate ply pattern, for the individual members identified in Figure 2 , is given in Table II.

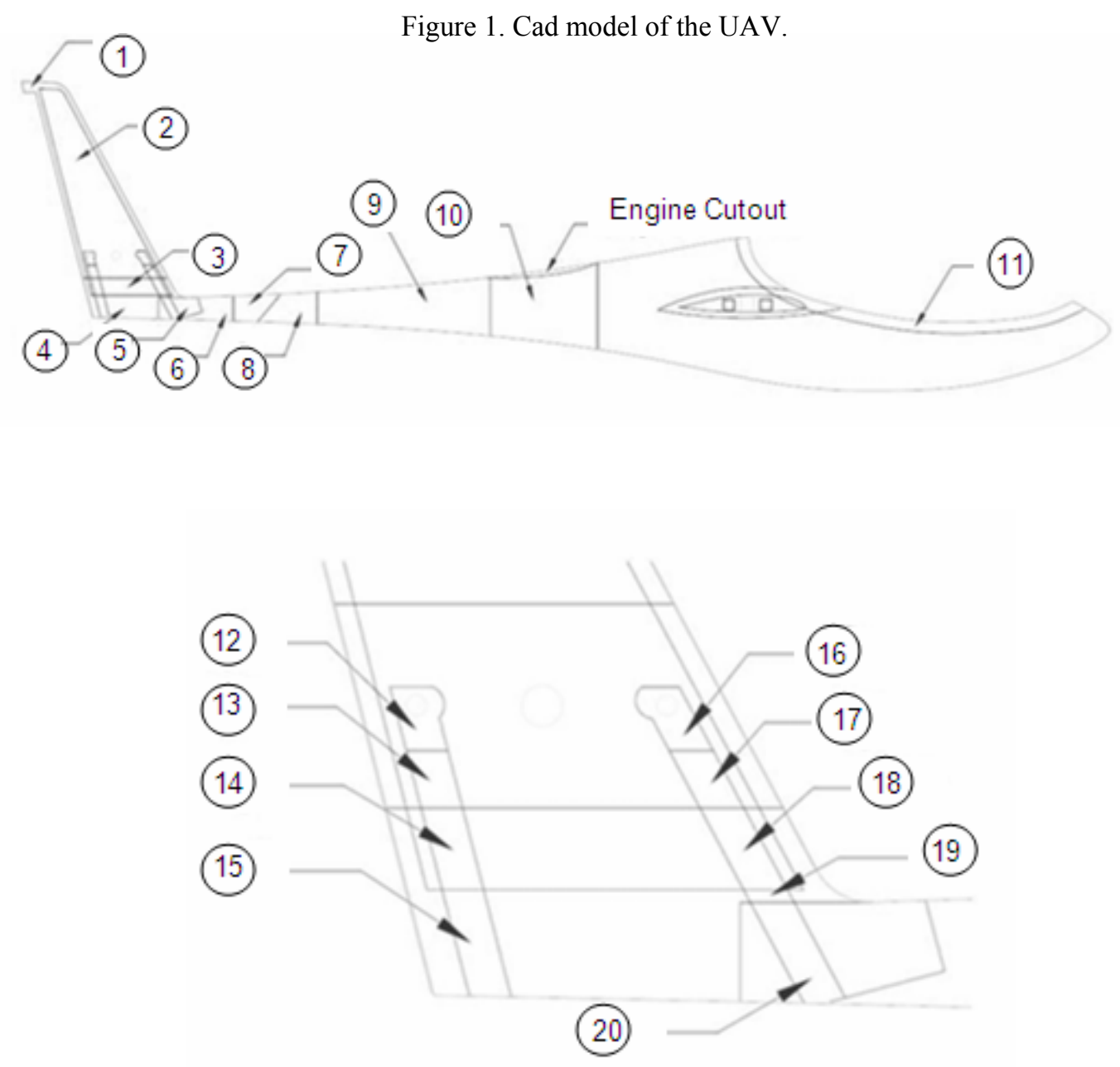

Figure 2. Structural Components of the fuselage/ vertical stabilizer. 
TABLE I: PHYSICAL AND ENGINEERING PROPERTIES OF MATERIALS.

\begin{tabular}{|ccccc|}
\hline $\begin{array}{c}\text { Material } \\
\text { Property }\end{array}$ & $\begin{array}{c}\text { Woven } \\
\text { Fabric }\end{array}$ & $\begin{array}{c}\text { Unidirectional } \\
\text { Fabric }\end{array}$ & $\begin{array}{c}\text { Dyvinicel } \\
\text { Foam }\end{array}$ & HC \\
\hline \hline$E_{11}, \mathrm{psi}$ & $8.03 \times 10^{6}$ & $1.73 \times 10^{7}$ & $1.233 \times 10^{4}$ & $3.50 \times 10^{3}$ \\
$E_{22}, \mathrm{psi}$ & $8.03 \times 10^{6}$ & $1.35 \times 10^{6}$ & $1.233 \times 10^{4}$ & $3.50 \times 10^{3}$ \\
$G_{12}, \mathrm{psi}$ & $6.10 \times 10^{5}$ & $6.10 \times 10^{5}$ & $1.233 \times 10^{4}$ & $5.00 \times 10$ \\
$G_{13}, \mathrm{psi}$ & $6.10 \times 10^{5}$ & $6.10 \times 10^{5}$ & $2.76 \times 10^{3}$ & $5.80 \times 10^{3}$ \\
$G_{23}, \mathrm{psi}$ & $6.10 \times 10^{5}$ & $6.10 \times 10^{5}$ & $2.76 \times 10^{3}$ & $2.00 \times 10^{4}$ \\
$v_{12}$ & $3.00 \times 10^{-2}$ & $3.10 \times 10^{-1}$ & $3.20 \times 10^{-1}$ & $5.00 \times 10^{-1}$ \\
$\rho, \mathrm{lb} / \mathrm{in}^{3}$ & $1.40 \times 10^{-4}$ & $1.427 \times 10^{-4}$ & $4.65 \times 10^{-6}$ & $4.49 \times 10^{-6}$ \\
\hline
\end{tabular}

TABLE II. LAMINATE DEFINITION OF STRUCTURAL PARTS IN FIGURE 2.

\begin{tabular}{|c|c|c|}
\hline Part No. & No. of Plies & Stacking Sequence $^{\mathrm{a}}$ \\
\hline 1 & 4 & $(50 / 15)_{s}$ \\
\hline 2 & 5 & $(50 / \text { foam } / 15 / 15 / 50)_{\mathrm{T}}$ \\
\hline 3 & 6 & $(50 / \text { foam } / 15 / 0 / 15 / 50)_{\mathrm{T}}$ \\
\hline 4 & 5 & $(50 / 15 / 0 / 15 / 50)_{\mathrm{T}}$ \\
\hline 5 & 6 & $(50 / 0 / 15 / 0 / 15 / 50)_{\mathrm{T}}$ \\
\hline 6 & 5 & $(50 / 0 / 15 / 0 / 50)_{\mathrm{T}}$ \\
\hline 7 & 5 & $(50 / 0 / 15 / 0 / 45)_{\mathrm{T}}$ \\
\hline 8 & 4 & $(50 / 0)_{\mathrm{s}}$ \\
\hline 9 & 4 & $(45 / 0)_{\mathrm{s}}$ \\
\hline 10 & 9 & $\left(45 / 0_{2} / 45 / \mathrm{HC} / 45 / 0_{2} / 45\right)_{\mathrm{T}}$ \\
\hline 11 & 4 & $\left(45_{3} / 0_{2} / 45\right)_{\mathrm{T}}$ \\
\hline 12 & 15 & $\left(50 / \text { foam } / 15 / 15 / 50 / 0 / 45_{3} / 0_{2} / 45_{3} / 0\right)_{\mathrm{T}}$ \\
\hline 13 & 12 & $\left(50 / \text { foam } / 15 / 15 / 50 / 0 / 45_{2} / 0 / 45_{2} / 0\right)_{\mathrm{T}}$ \\
\hline 14 & 13 & $\left(50 / \text { foam } / 15 / 0 / 15 / 50 / 0 / 45_{2} / 0 / 45_{2} / 0\right)_{\mathrm{T}}$ \\
\hline 15 & 12 & $\left(50 / 15 / 0 / 15 / 50 / 0 / 45_{2} / 0 / 45_{2} / 0\right)_{\mathrm{T}}$ \\
\hline 16 & 11 & $(50 / \text { foam } / 15 / 15 / 50 / 0 / 45 / 0 / 45 / 0 / 45)_{\mathrm{T}}$ \\
\hline 17 & 8 & $(50 / \text { foam } / 15 / 15 / 50 / 45 / 0 / 45)_{\mathrm{T}}$ \\
\hline 18 & 9 & $(50 / \text { foam } / 15 / 0 / 15 / 50 / 45 / 0 / 45)_{\mathrm{T}}$ \\
\hline 19 & 8 & $(50 / 15 / 0 / 15 / 50 / 45 / 0 / 45)_{\mathrm{T}}$ \\
\hline 20 & 9 & $(50 / 0 / 15 / 0 / 15 / 50 / 45 / 0 / 45)$ \\
\hline
\end{tabular}


${ }^{\mathrm{a}} \theta$ is $\pm \theta$ fabric, and $\mathrm{HC}$ is honeycomb core.

\section{EXPERIMENTAL SETUP AND PROCEDURE}

The modal characteristics of the fuselage structure are determined for a free-free configuration which is simulated by suspending the fuselage structure from the wing attachment points. Figure 3 shows the fuselage body mounted in the universal test system (UTS). Designed to match the wing/ fuselage connection points, the test fixture is suspended from the support beam of the UTS by two large springs, which are connected to the fixture through turnbuckles as shown in Figure 4. The shaker system, which is centrally attached to the bottom member of the test fixture (Figure 4) via a steel stinger rod, is used to induce vertical oscillations in the structure.

The data acquisition setup for the vibration testing is shown in Figure 5. Single input excitation, provided by an arbitrary waveform function generator, is used to excite the 110-lb capacity shaker unit. A dynamic force transducer is connected in series with the shaker to obtain the input force signal to the fuselage/tail body. Because lateral movement of the test article can cause damage to the delicate shaker unit and force transducer, careful consideration is taken to properly balance and mount the test structure. The open loop system records the acceleration data for either a range of frequencies or a particular frequency at user selected sampling rates through a LabVIEW® program.

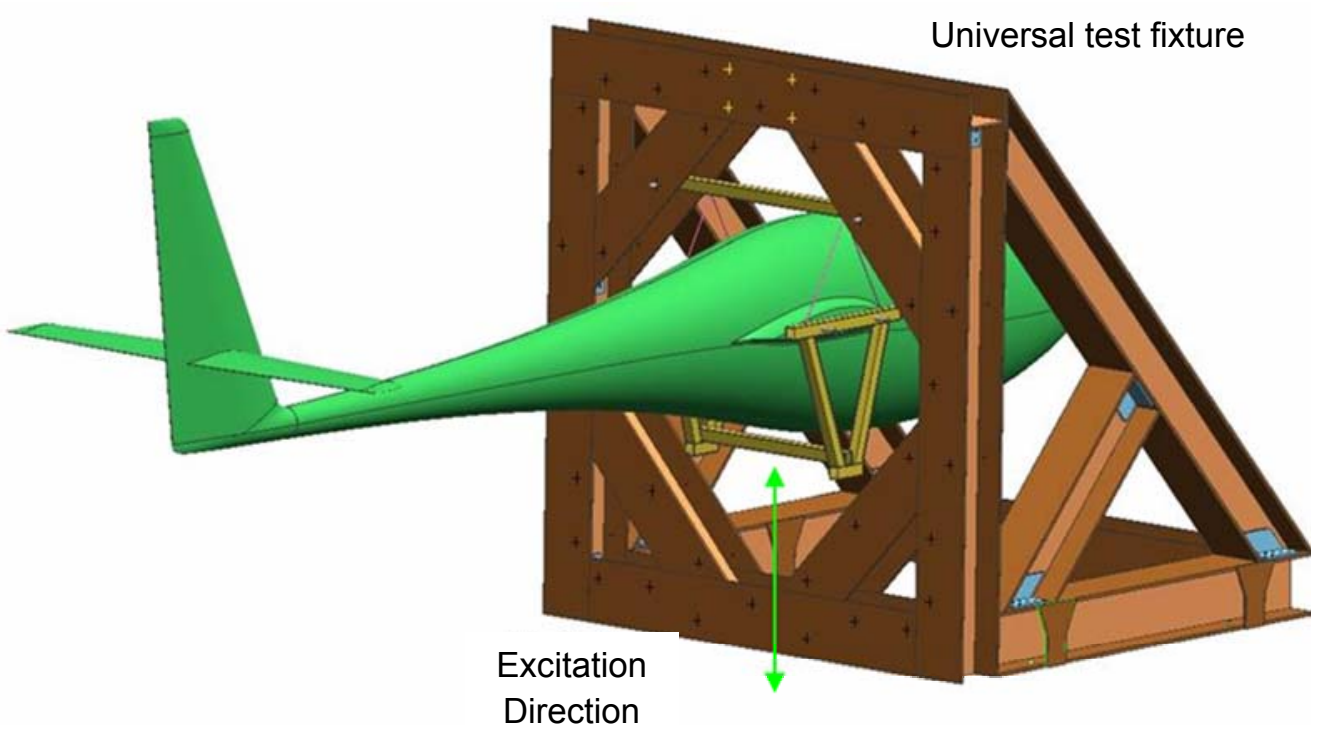

Figure 3. Fuselage Vibration Test Setup. 


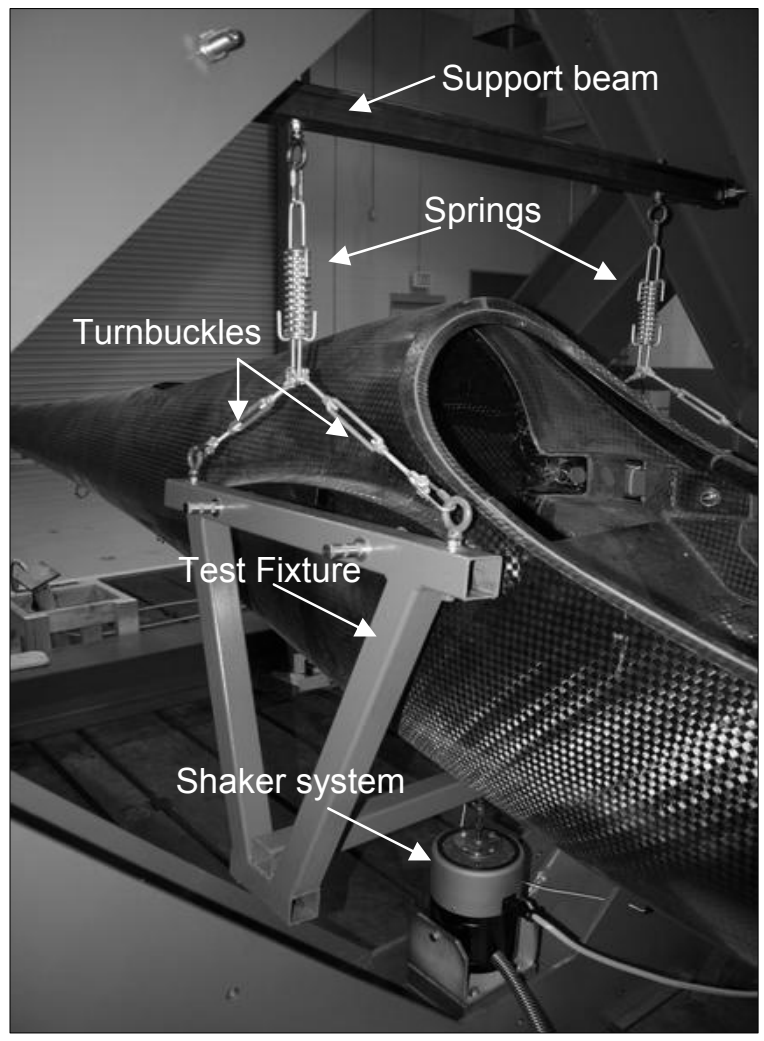

Figure 4. Fuselage Vibration Test Fixture.

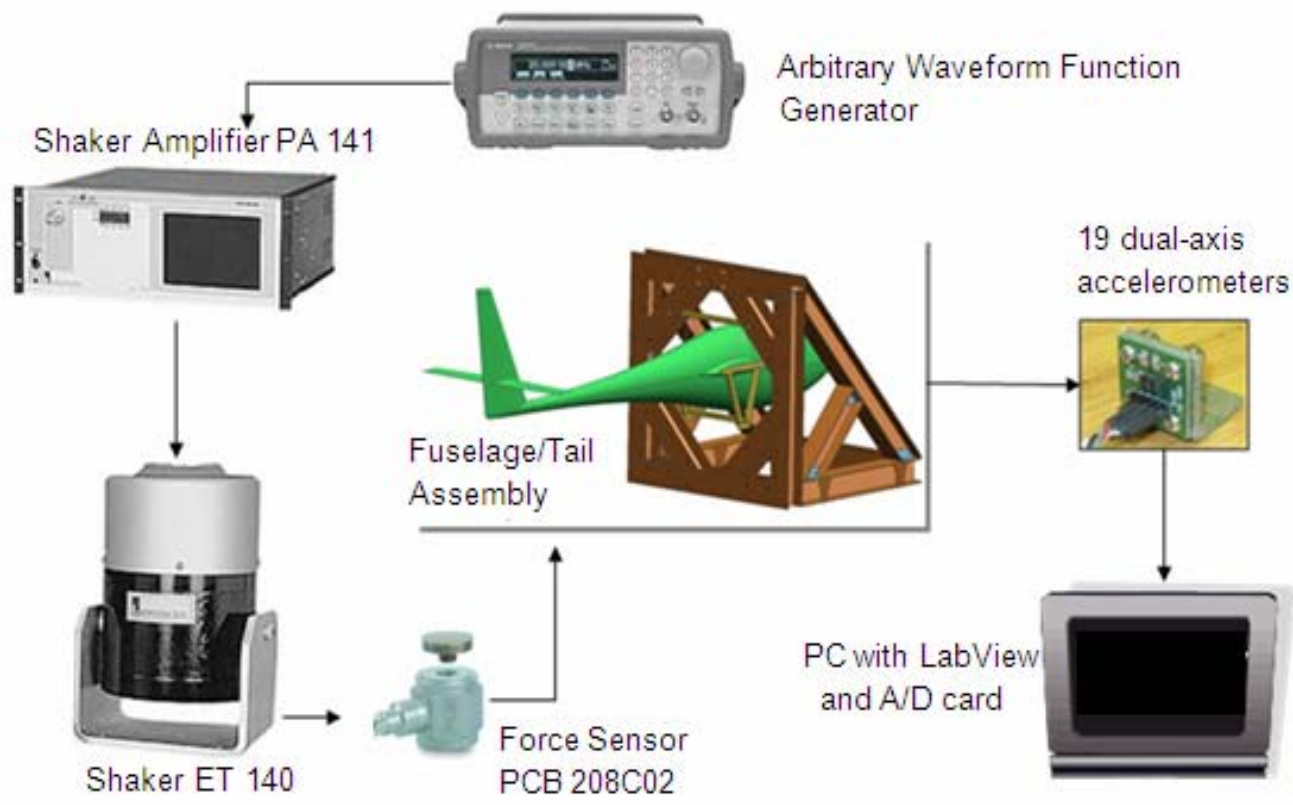

Figure 5: Vibration data acquisition system 


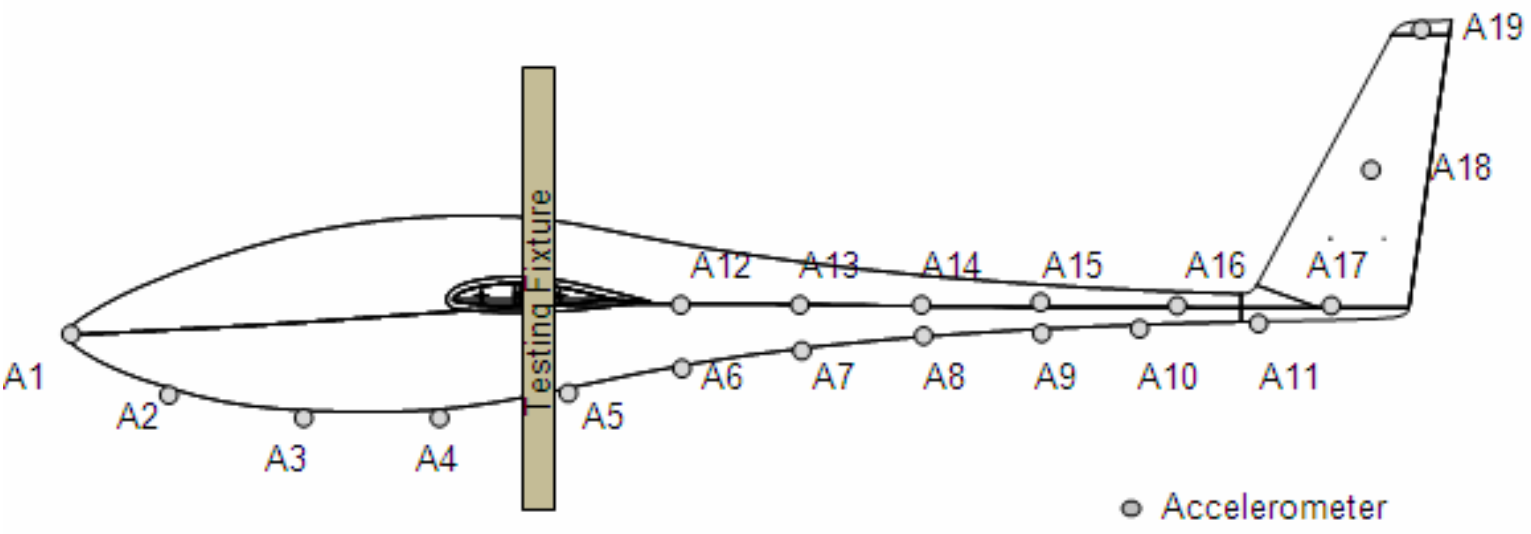

Figure 6. Fuselage Vibration Testing Configuration \#1

To obtain the vibration characteristics, the structure is instrumented with 19 dual-axis accelerometers (ADXL321), which have an average sensitivity of 0.057 $\mathrm{mV} / \mathrm{g}$ and a range of $\pm 18 \mathrm{~g}$. The lightweight accelerometers are mounted with double-sided adhesive tape such that in-plane and out-of-plane responses are measured. The vibration characteristics of the structure are obtained from the sensor configuration shown in Figure 6. In this configuration, the first 11 sensors (A1-A11) are located along the bottom of the fuselage body, equidistantly spaced from nose to tail. The next four accelerometers (A12-A16) are mounted on the left aft side of the fuselage and the remaining three accelerometers (A17-A19) are mounted on the left side of the vertical tail. Vibration tests are also conducted for an additional three sensor configurations to verify the modal data obtained from the configuration shown in Figure 6. In each configuration, a total of 38 discrete-point accelerations are measured and recorded.

The swept sine technique [2-5] is used and frequency sweeps from $3 \mathrm{~Hz}$ to 100 $\mathrm{Hz}$ are conducted at a sampling rate of $500 \mathrm{~Hz}$. To obtain the modal parameters, the input force signal and the response from each sensor is recorded for later processing.

\section{ANALYTICAL METHODOLOGY}

One of the tools used for obtaining modal properties of a structure is through the use of transfer functions in the frequency domain called frequency response functions (FRF). These functions can be based on the displacement, velocity or acceleration response of the system. In this study, the resulting transfer function, based on the acceleration response and known as the accelerance, is depicted by the linear model shown in Figure 7 [6-9]. 


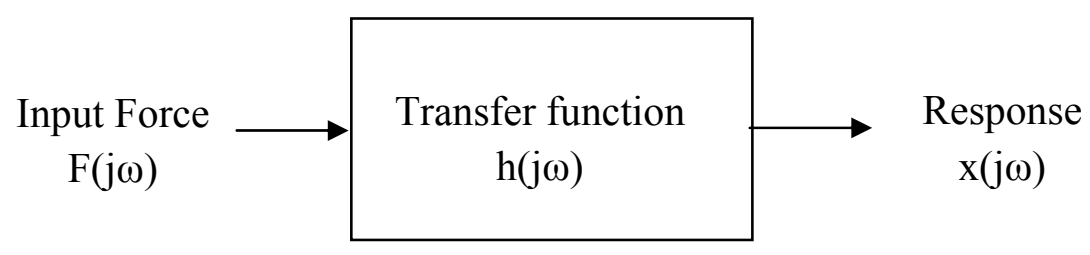

Figure 7. Linear model for a FRF.

From this model, it is seen that the transfer function $\mathrm{h}(\mathrm{j} \omega)$, is simply the ratio of the spectrum of the response signal $x(j \omega)$ to the spectrum of the applied force signal $F(j \omega)$, and can be expressed as

$$
h(j \omega)=\frac{x(j \omega)}{F(j \omega)}
$$

To obtain the spectrum $x(j \omega)$ and $F(j \omega)$, the Discrete Fourier Transform (DFT) $[8,9]$ of the input signal (applied force) and the output response (acceleration) from each channel is computed from Equation (2) as

$$
c_{j}=\frac{1}{n} \sum_{p} d_{p} e^{i\left(\frac{2 \pi j}{n}\right) p}
$$

where $n$ is the number of elements in the input or output response vector $d_{p}$. The frequency corresponding to the $p^{\text {th }}$ element in the calculated transfer function is given by

$$
f_{p}=\frac{p}{n} f_{s}
$$

where $f_{s}$ is the sampling frequency of the original signal. Once the DFT of each signal is obtained, the transfer function in Equation (1) is computed. Both the resonant frequencies and the corresponding mode shapes are obtained from the plot of the imaginary component of the resulting FRFs and verified by integrating the acceleration data twice to obtain the displacement at each sensor location.

Additionally, the damping ratio $\xi$, which is defined as the natural tendency of the structure to return to an equilibrium state after being oscillated, is determined for each resonant frequency. Using half power points, the damping ratio is calculated as

$$
\xi=\frac{\omega_{2}-\omega_{1}}{2 \omega_{n}}
$$

where the bandwidth $\left(\omega_{1}-\omega_{2}\right)$ is located at 0.707 times the peak amplitude. The structural damping coefficient is simply twice the damping ratio.

\section{RESULTS \& DISCUSSION}

The g-load data from all sensors and configurations is analyzed and the frequency response functions are computed by using the spectrum of the input (applied force) 
and output signals (acceleration) in Equation (1). Figure 8 shows the FRF of accelerometer A19, which is located at the tip of the vertical stabilizer. Similar FRF plots for all accelerometers were computed and the magnitude and direction at each resonant frequency was determined to obtain the mode shape associated with each natural frequency.

Although frequency sweeps were conducted in the range of $3 \mathrm{~Hz}$ to $100 \mathrm{~Hz}$, only data up to $50 \mathrm{~Hz}$ is shown as there are no resonant frequencies that appear in the $50 \mathrm{~Hz}$ to $100 \mathrm{~Hz}$ range. In the figures depicting the modal data, the coordinate system shown in Figure 9 is used. The two axes of measurement for the accelerometers on the bottom of the fuselage (A1-A11) are the x-axis (lateral) and the y-axis (vertical/ up-down), whereas the two axes of measurement for accelerometers on the left aft side of the fuselage (A12-A16) are the x-axis (lateral) and $\mathrm{z}$-axis (longitudinal) and for the accelerometers on the tail (A17-A19), the lateral axis is represented by the $\mathrm{x}$-axis and the chordwise (in-plane) direction is described by the z-axis.

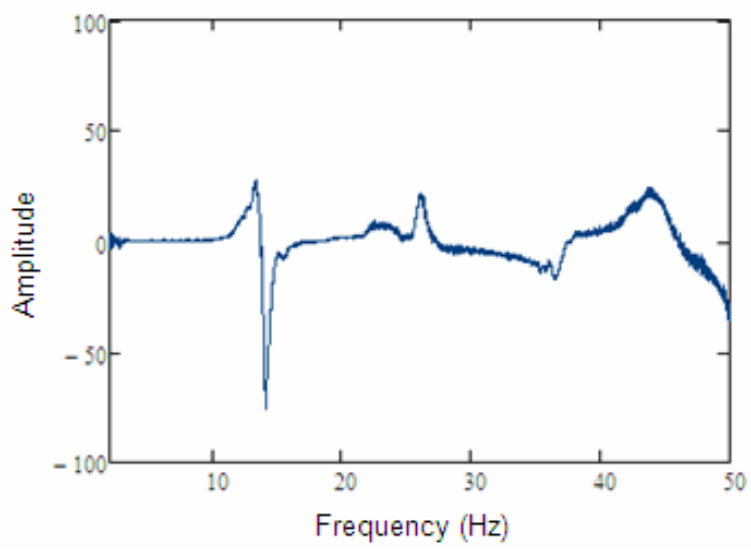

Figure 8. FRF of accelerometer A19.

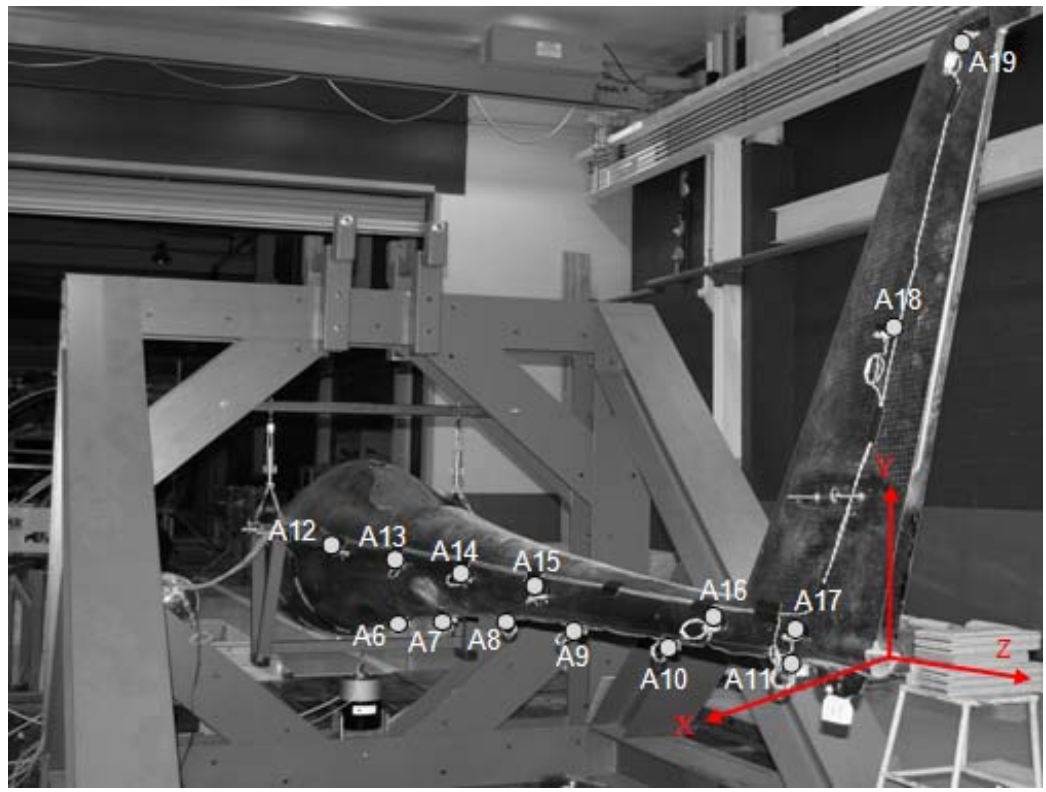

Figure 9: Displacement direction of the test structure 
Figures 10a and $10 \mathrm{~b}$ show the frequency spectrums computed from the acceleration data for accelerometers $\mathrm{A} 1, \mathrm{~A} 8$ and $\mathrm{A} 10$, in the $\mathrm{x}$ and $\mathrm{y}$-directions, respectively. As can be seen from both figures, all three sensors depict most of the same natural frequencies but with varying amplitudes. The presence of resonant frequencies in both axes indicates a combination of modes. For example, the amplitude at the first resonant frequency of $13.5 \mathrm{~Hz}$ is greatly diminished in the $\mathrm{y}$ direction when compared to the $\mathrm{x}$-direction which is indicative of the predominance of a lateral bending mode simultaneously with slight vertical bending. Conversely, at $25.4 \mathrm{~Hz}$, the amplitude of the data in the y-direction is much larger, which indicates the predominance of a vertical bending mode.

Figures $11 \mathrm{a}$ and $11 \mathrm{~b}$ show the frequency spectrums for the $\mathrm{x}$ and $\mathrm{z}$ directions for accelerometers A14 and A16. These accelerometers are located on the aft side of the fuselage. Minimal response is obtained from the out-of-plane (x-axis) channels (Figure 11a), but in the z-direction (Figure 11b), which is the longitudinal axis of the fuselage, the spectrums show small amplitude peaks at all the natural frequencies.

The frequency spectrums in the $\mathrm{x}$ and $\mathrm{z}$ directions for accelerometers A17, A18, A19, located on the left side of the vertical stabilizer, are shown in Figures 12a and $12 \mathrm{~b}$, respectively. As expected, amplitudes at the resonant frequencies on the vertical stabilizer are much larger in magnitude than those obtained from the fuselage body. It is seen that although the first natural frequency of $13.5 \mathrm{~Hz}$ appears in both directions, the peak amplitude in the $\mathrm{x}$-direction is much larger than the amplitude in the $\mathrm{z}$-direction, indicating lateral bending of the tail as the predominant mode, which is clearly observed during test. It is also noted that the second peak at approximately $25 \mathrm{~Hz}$ is significant in the z-direction, indicating a chordwise motion, which is also visible during testing. Figures $12 \mathrm{a}$ and $12 \mathrm{~b}$ also show the minimal response of A17, which is expected since it is located at the root of the vertical stabilizer.

The resulting mode shapes at $13.5 \mathrm{~Hz}, 24.6 \mathrm{~Hz}, 36.3 \mathrm{~Hz}$ and $45.2 \mathrm{~Hz}$ are shown in Figure 13. The lateral bending of the tail at the first frequency as well as the chordwise motion at the second frequency is evident from these figures. As expected, due to the complex structure geometry, all vibration modes are mixed modes having some combination of bending and torsion. Table III summarizes the modal characteristics (resonant frequencies, mode shapes, and associated damping ratios) of the fuselage/tail structure obtained from the FRFs of each sensor channel. All data was post-processed using Mathcad and MATLAB programs. 


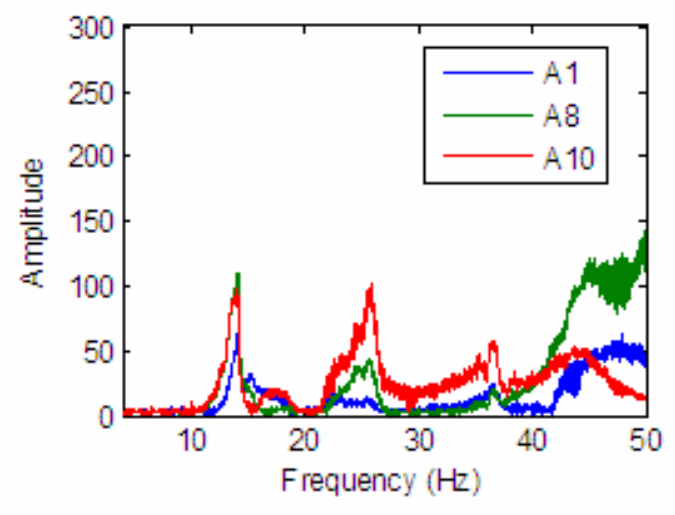

(a)

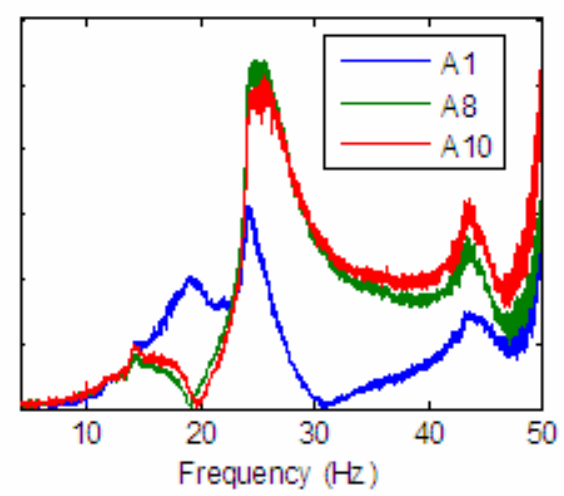

(b)

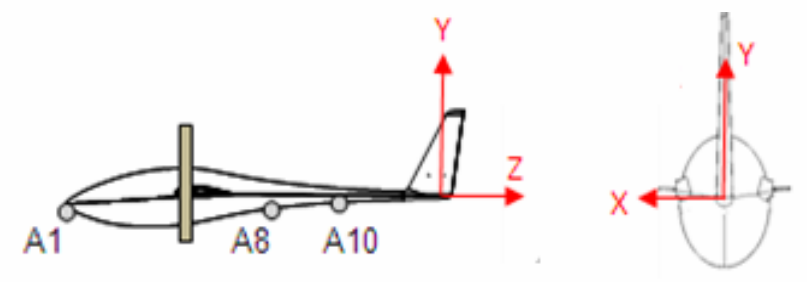

(c)

Figure 10. Frequency spectrums for A1, A8, and A10 in the (a) x-direction and (b) y- direction using (c) the coordinate system.

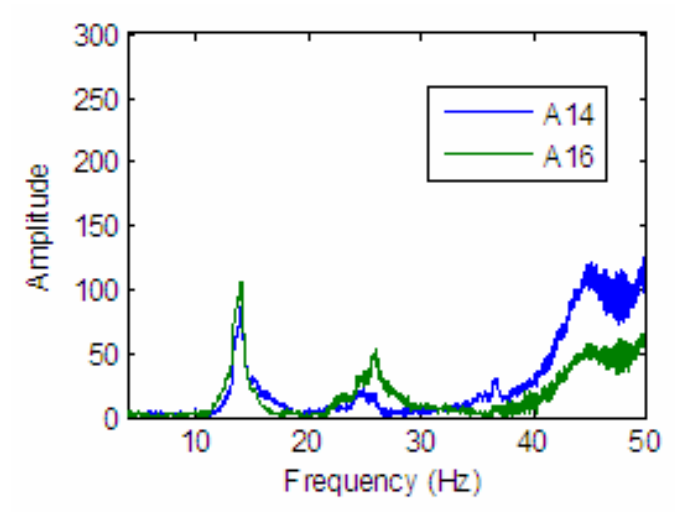

(a)

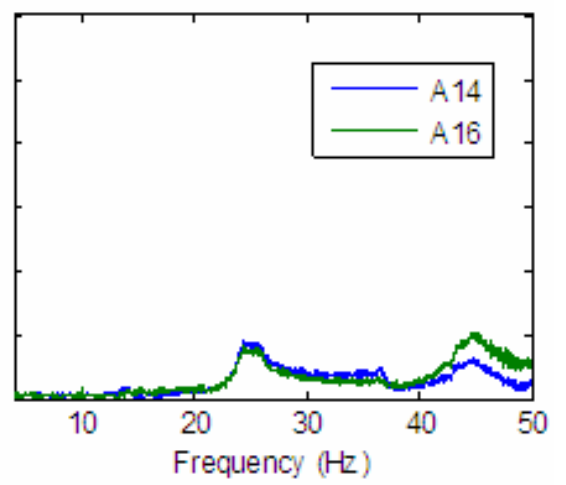

(b)

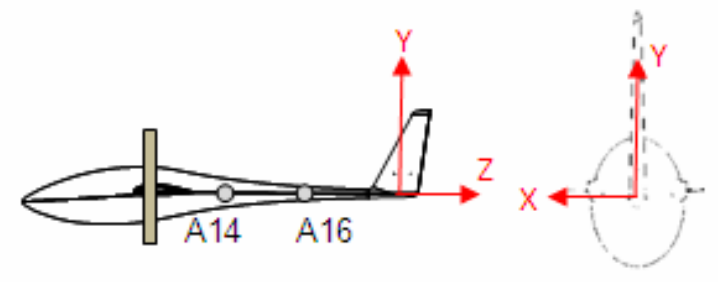

(c)

Figure 11. Frequency spectrums of A14 and A16 in the (a) x-direction and (b) z- direction using (c) the coordinate system. 


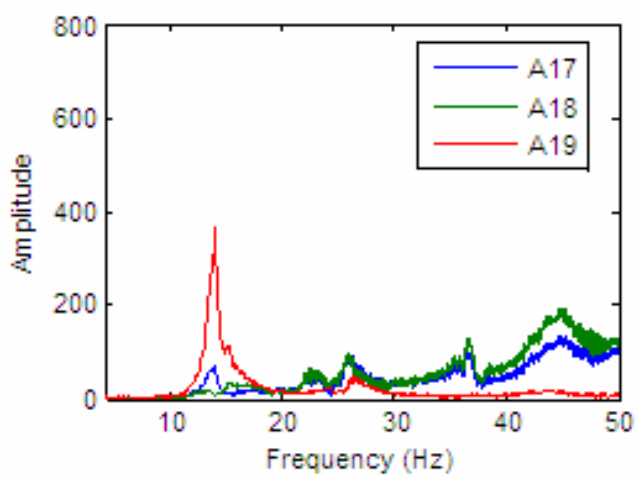

(a)

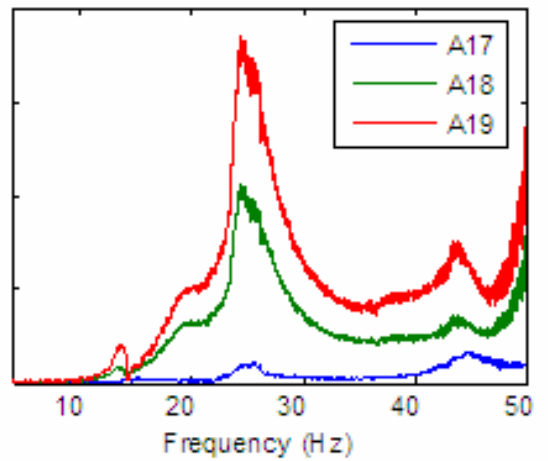

(b)

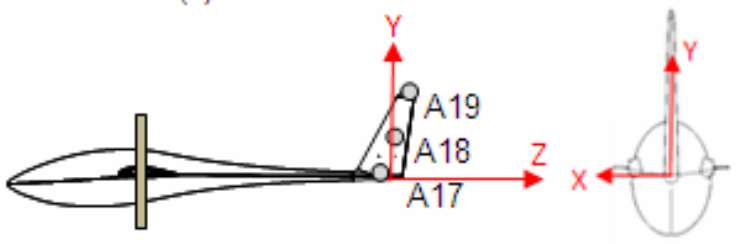

(c)

Figure 12. Frequency spectrums of A17, A18, and A19 in (a) x direction and (b) z-direction using (c) the coordinate system.

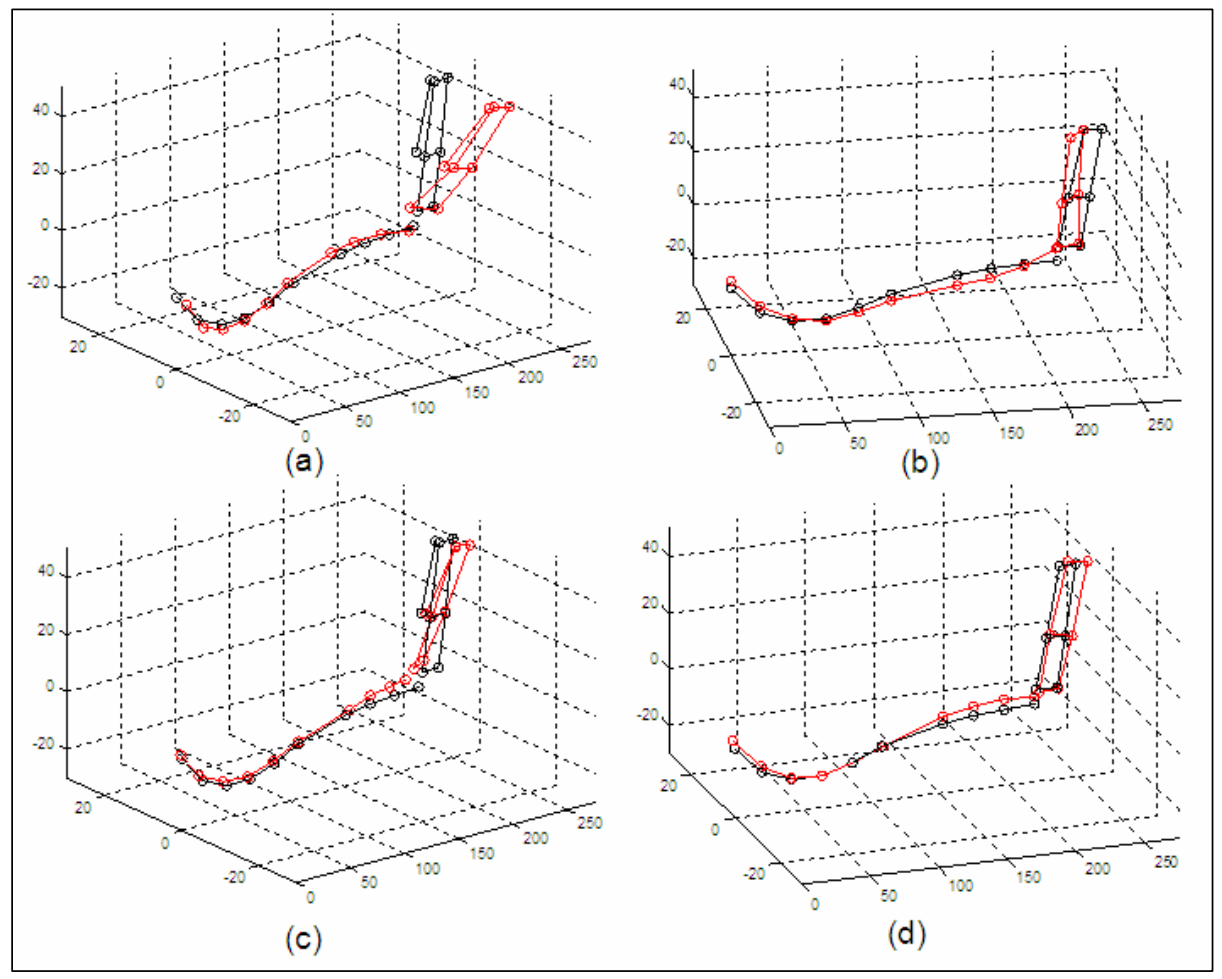

Figure 13: Red-mode shape at (a) $13.5 \mathrm{~Hz}$ (b) $24.6 \mathrm{~Hz}$ (c) $36.3 \mathrm{~Hz}$ (d) $45.2 \mathrm{~Hz}$. Black-mode shape at $0 \mathrm{~Hz}$ 
TABLE III. RESONANT FREQUENCIES AND ITS CORRESPONDING DAMPING RATIO AND OBSERVED MODE SHAPE OF FUSELAGE/TAIL STRUCTURE

\begin{tabular}{|c|c|c|c|}
\hline Peak No. & $\begin{array}{c}\text { Natural } \\
\text { Frequency }\end{array}$ & $\begin{array}{c}\text { Damping } \\
\text { Ratio }\end{array}$ & Observed Primary Mode \\
\hline \hline 1 & $13.5 \mathrm{~Hz}$ & 0.07 & Lateral bending \\
\hline 2 & $24.6 \mathrm{~Hz}$ & 0.04 & $\begin{array}{c}\text { Vertical tail - chordwise bending } \\
\text { Fuselage - vertical bending }\end{array}$ \\
\hline 3 & $26.1 \mathrm{~Hz}$ & 0.15 & Lateral bending \\
\hline 4 & $36.3 \mathrm{~Hz}$ & 0.21 & $\begin{array}{c}\text { Vertical tail - lateral bending } \\
\text { Fuselage - vertical bending }\end{array}$ \\
\hline 5 & $45.4 \mathrm{~Hz}$ & 0.17 & $\begin{array}{c}\text { Vertical tail - lateral bending } \\
\text { Fuselage - vertical bending }\end{array}$ \\
\hline
\end{tabular}

\section{CONCLUSIONS}

The modal characteristics of a carbon composite fuselage/ tail structure of an UAV are determined for a free-free configuration. Nineteen dual axis accelerometers are used to determine the dynamic characteristics of the structure. Using the swept-sine technique, g-load data is obtained for a range of desired frequencies. Frequency response functions are computed to determine the resonant frequencies and the associated mode shapes and damping coefficients. The methodology presented here proved to be a simple and effective procedure from which the modal characteristics of a large component are determined.

\section{ACKNOWLEDGMENT}

The funding provided for this study by US Army SMDC under Contract No. DASG60-01-C-0038 is gratefully acknowledged.

\section{REFERENCES}

1. Sullivan, R., Rais-Rohani, M., Lacy, T., and Alday, N. 2006. "Structural Testing of an Ultralight UAV Composite Wing," presented at the $47^{\text {th }}$ AIAA/ASME/ASCE/AHS/ASC Structures, Structural Dynamics, and Material Conference, Newport, Rhode Island, 1-4 May 2006.

2. Kehoe, Michael W. 1987. "Aircraft Ground Vibration Testing at NASA Ames-Dryden Flight Research Facility,” NASA TM-88272.

3. Kehoe, Michael W., and D. Voracek. 1994. "Ground Vibration Test Results of a JetStar Airplane Using Impulsive Sine Excitation,” NASA TM-100448.

4. Cox, Timothy H., and Glenn B. Gilyrad. 1986. "Ground Vibration Test Results for Drones for Aerodynamic and Structural Testing (DAST) / Aeroelastic Research Wing (ARW-1R) Aircraft," NASA TM-85906.

5. ADS-27 Aeronautical Design Standard, Requirements for Rotorcraft Vibration Specifications, Modeling and Testing, June 1993.

6. Avitabile, Peter. "Experimental Modal Analysis - A Simple Non-Mathematical Presentation," Sound and Vibration, January 2001. 
7. T. Irvine. 1990. "The Steady-state Response of a Single-degree-of-freedom System Subjected to a Harmonic Force", Vibrationdata.com Publications.

8. Rao, Singiresu. 2003. Mechanical Vibrations, $4^{\text {th }}$ ed., Prentice Hall, New Jersey, pp. 759-783.

9. Thomson, Willam T., and M. Dahleh. 1993. Theory of Vibration with Applications, $5^{\text {th }}$ ed. , Prentice Hall, New Jersey. pp. 231-267. 